\title{
Multicenter Prospective Study of Laparoscopic Nissen Fundoplication for Gastroesophageal Reflux Disease in Korea
}

\author{
Sungsoo Park, ${ }^{1}$ Joong-Min Park, ${ }^{2 *}$ Jin-Jo Kim, $^{3}$ In-Seob Lee, ${ }^{4}$ Sang-Uk Han, ${ }^{5}$ Kyung Won Seo, ${ }^{6}$ and Jin Won Kwon ${ }^{7}$ \\ ${ }^{1}$ Department of Surgery, Korea University College of Medicine, Seoul, Korea; ${ }^{2}$ Department of Surgery, Chung-Ang University College of \\ Medicine, Seoul, Korea; ${ }^{3}$ Department of Surgery, The Catholic University of Korea College of Medicine, Incheon, Korea; ${ }^{4}$ Department of Surgery, \\ University of Ulsan College of Medicine and Asan Medical Center, Seoul, Korea; ${ }^{5}$ Department of Surgery, Ajou University College of Medicine, \\ Suwon, Korea; ${ }^{6}$ Department of Surgery, Kosin University College of Medicine, Busan, Korea; and ${ }^{7}$ Department of Pharmacy, Kyungpook \\ National University, Daegu, Korea
}

\section{Backgrounds/Aims}

This multicenter study aims to evaluate the effect and feasibility of anti-reflux surgery compared with medical treatment for gastroesophageal reflux disease (GERD).

\section{Methods}

Patients with GERD who were undergoing medical treatment with proton pump inhibitors for more than 8 weeks and those who were scheduled to undergo anti-reflux surgery were enrolled. Efficacy of pre-operative medical treatment was evaluated retrospectively and effect of anti-reflux surgery was prospectively evaluated at 1 week and 3 months after surgery. Quality of life (QOL) was also investigated before and after surgery.

\section{Results}

Between February and October 2018, 51 patients underwent laparoscopic Nissen fundoplication for treating GERD at 5 hospitals in Korea. Thirty-four patients (66.7\%) showed poor proton pump inhibitor response. At 3 months after surgery, heartburn was completely resolved in $87.9 \%$ patients and partially improved in $9.1 \%$. Acid regurgitation was completely resolved in $82.9 \%$ and partially improved in $11.4 \%$. Atypical extraesophageal symptoms were completely controlled in $45.5 \%$ and partially controlled in 36.4\%. GERD-related QOL scores at 1 week after surgery significantly improved compared with pre-operative scores. There was no difference in GERD-related QOL scores between 1 week and 3 months after surgery. General QOL measured with European QOL-5 dimensions and health-related QOL instrument with 8 items significantly improved after anti-reflux surgery. Satisfaction with treatment was significantly higher after surgery than before surgery $(72.5 \%$ vs $11.8 \%, P<0.001)$.

\section{Conclusion}

Anti-reflux surgery improved GERD symptoms and QOL in patients. Anti-reflux surgery is an effective treatment option compared with medical treatment for GERD patients selected for surgical treatment.

\section{(J Neurogastroenterol Motil 2019;25:394-402)}

Key Words

Fundoplication; Gastroesophageal reflux; Laparoscopy; Quality of life

Received: March 21, 2019 Revised: May 16, 2019 Accepted: May 27, 2019

(a) This is an Open Access article distributed under the terms of the Creative Commons Attribution Non-Commercial License (http://creativecommons. org/licenses/by-nc/4.0) which permits unrestricted non-commercial use, distribution, and reproduction in any medium, provided the original work is properly cited.

*Correspondence: Joong-Min Park, MD, PhD

Department of Surgery, Chung-Ang University College of Medicine, 102 Heukseok-ro, Dongjak-gu, Seoul 06973, Korea Tel: +82-2-6299-3124, Fax: +82-2-6299-2064, E-mail: jmpark@cau.ac.kr 


\section{Introduction}

Laparoscopic fundoplication is regarded as an alternative treatment method to medical treatment with acid-suppressive drugs for gastroesophageal reflux disease (GERD) in Western countries, where the prevalence of GERD is relatively high. ${ }^{1}$ However, despite the increased interest in anti-reflux surgery owing to the increased prevalence of GERD, the awareness of anti-reflux surgery is still inadequate, and almost all patients with GERD are managed with medication in Korea. According to the National Health Insurance Service data, 342 GERD patients underwent anti-reflux surgery between 2012 and 2016, whereas 3.1 million patients underwent medical treatment with proton pump inhibitors (PPIs) during the same period in Korea.

Despite this, the number of anti-reflux surgeries in Korea has recently increased, and there have been several studies reporting the outcome of anti-reflux surgery. ${ }^{2-5}$ However, there are no prospective studies comparing the efficacy of anti-reflux surgery and its effect on quality of life (QOL) with medical treatment.

The aim of this multicenter study is to evaluate the feasibility of anti-reflux surgery and its effect on reflux symptoms and QOL compared with medical therapy for GERD.

\section{Materials and Methods}

\section{Patients}

GERD was diagnosed when reflux esophagitis was observed on endoscopy in a patient with typical symptoms, Barrett's esophagus was observed on endoscopic biopsy, or peptic stricture was observed in the absence of malignancy, or positive $\mathrm{pH}$ monitoring study. Patients with GERD who were undergoing medical treatment with PPIs for more than 8 weeks and who were scheduled to undergo anti-reflux surgery were enrolled in the study. Reasons for undergoing surgery were failed medical treatment or patient preference of discontinuing life-long medication despite the medical treatment being successful. Patients aged less than 18 years at surgery and those who had previously undergone anti-reflux surgery or endoscopic anti-reflux procedure were excluded.

Five surgeons from 5 university hospitals in Korea participated in this study. Each surgeon was a specialist in upper gastrointestinal surgery and had conducted at least 30 laparoscopic fundoplications before the study.

\section{Data Collection}

After obtaining approval from the institutional review boards of the 5 participating hospitals; Chung-Ang University Hospital (IRB No. 1810-001-308), Korea University Anam Hospital (IRB No. AN17232-001), Incheon St. Mary's Hospital (IRB No. OC18QEDE0014), Asan Medical Center (IRB No. 2018-0803), and Ajou University Hospital (IRB No. AJIRB-ME-OBS-17-484), we retrospectively evaluated the disease status and medical treatments before enrollment, and prospectively evaluated surgical treatment outcomes after enrollment in the study.

Pre-operative demographic characteristics, GERD symptoms, and information on medical treatment were noted. As diagnostic workup for anti-reflux surgery, gastroscopy, barium esophagogastrography, esophageal manometry, and esophageal $\mathrm{pH}$ monitoring test were recommended, and the results of these diagnostic tests were collected. After surgery, short-term and long-term surgical complications were investigated. Degree of improvement of GERD symptoms and post-operative adverse symptoms were evaluated 2 times, 1 week after surgery and 3 months after surgery. The patients were asked to report any change in their GERD symptoms. Changes in individual GERD symptoms were reported as complete resolution, partial resolution, no change, and worsened symptoms. Adverse symptoms comprising dysphagia, difficult belching, gas bloating, and hyperflatulence were reported using a 4-point scale (no symptom, mild, moderate, and severe).

QOL for GERD patients was investigated before and after anti-reflux surgery using questionnaires. GERD-related QOL was measured by the means of GERD health-related QOL (GERDHRQL) questionnaire, developed to evaluate the therapeutic effect of GERD. ${ }^{6}$ We modified the GERD-HRQL to additionally evaluate atypical symptoms (Supplementary Table). Heartburn scores and regurgitation scores were calculated based on 6 questions concerning heartburn and acid regurgitation, as in the original GERD-HRQL, and the atypical symptom scores were calculated based on 6 additional questions about atypical symptoms. The total GERD score was calculated using the GERD symptom scores and the score for additional question about swallowing difficulty.

European QOL-5 dimensions (EQ-5D) and health-related QOL instrument with 8 item (HINT-8) questionnaires were used to assess general QOL at baseline (before surgery), 1 week after surgery, and 3 months after surgery. The EQ-5D questionnaire, developed by the EuroQol group, consisted of a descriptive system and visual analogue scale (VAS). The descriptive system was comprised of the following 5 dimensions: mobility, self-care, usual activ- 
ity, pain/discomfort, and anxiety/depression. The EQ VAS records the respondent's self-rated health on a vertical, visual analogue scale (from 0 to 100) where the endpoints are labeled "Best imaginable health state" and "Worst imaginable health state."

HINT-8 is the measurement instrument for Korean healthrelated QOL that was developed to be used in the Korea National Health and Nutrition Examination Survey. It consists of the following parameters: climbing stairs, endurance of pain, vitality, working, depression, memory, sleep, and happiness.

\section{Statistical Methods}

Statistical analysis was performed using the McNemar test to determine whether the proportion of patients without post-operative adverse symptoms changed from immediately after surgery to 3 months after surgery. The changes in QOL measurements were verified by paired $t$ test. Statistical analysis was performed using SPSS version 19.0 (IBM Corp, Armonk, NY, USA).

Table 1. Patient Demographics and Characteristics

\begin{tabular}{|c|c|}
\hline Characteristics & Values \\
\hline \multicolumn{2}{|l|}{ Sex } \\
\hline Male & $31(60.8)$ \\
\hline Female & $20(39.2)$ \\
\hline \multicolumn{2}{|l|}{ Age (yr) } \\
\hline$<29$ & $6(11.8)$ \\
\hline $30-39$ & $6(11.8)$ \\
\hline $40-49$ & $2(3.9)$ \\
\hline $50-59$ & $16(31.4)$ \\
\hline $60-69$ & $12(23.5)$ \\
\hline$>70$ & $9(17.6)$ \\
\hline $\operatorname{BMI}\left(\mathrm{kg} / \mathrm{m}^{2}\right)$ & $23.4 \pm 3.2(15.4,29.4)$ \\
\hline $\mathrm{BMI}<18$ & $2(3.9)$ \\
\hline $18 \leq \mathrm{BMI}<25$ & $31(60.8)$ \\
\hline $25 \leq \mathrm{BMI}<30$ & $18(35.3)$ \\
\hline $30 \leq \mathrm{BMI}$ & $0(0.0)$ \\
\hline \multicolumn{2}{|c|}{ Past abdominal surgery } \\
\hline No & $41(80.4)$ \\
\hline Yes & $10(19.6)$ \\
\hline \multicolumn{2}{|l|}{ Comorbidity } \\
\hline None & $31(60.8)$ \\
\hline Cardiovascular & $14(27.5)$ \\
\hline Diabetes & $4(7.8)$ \\
\hline Pulmonary & $2(3.9)$ \\
\hline Hepatobiliary & $3(5.9)$ \\
\hline Prostate & $2(3.9)$ \\
\hline Gout & $2(3.9)$ \\
\hline Osteoporosis & $1(2.0)$ \\
\hline
\end{tabular}

BMI, body mass index.

Values were expressed as $\mathrm{n}(\%)$ or mean $\pm \mathrm{SD}$ (range).

\section{Results}

\section{Patient Characteristics}

The baseline characteristics for patients are listed in Table 1. Of the 51 patients who underwent anti-reflux surgery between February and October 2018, 31 were male and 20 were female. The mean age was 53.3 years. Most patients were in their $50 \mathrm{~s}(31.4 \%)$,

Table 2. Symptoms of Gastroesophageal Reflux Disease and Medical Treatment Before Surgery

\begin{tabular}{|c|c|}
\hline Variables & Values \\
\hline Reflux symptom duration (mo) & $126.3 \pm 138.5(8,720)$ \\
\hline$<6$ & $0(0.0)$ \\
\hline $12-60$ & $2(3.9)$ \\
\hline $12-60$ & $14(27.5)$ \\
\hline $60-120$ & $7(13.7)$ \\
\hline $120-240$ & $20(39.2)$ \\
\hline$\geq 240$ & $8(15.7)$ \\
\hline \multicolumn{2}{|l|}{ Type of symptoms } \\
\hline Heartburn & $43(84.3)$ \\
\hline Regurgitation & $47(92.2)$ \\
\hline Dysphagia & $8(15.7)$ \\
\hline Epigastric pain & $17(33.3)$ \\
\hline Globus sense & $37(72.5)$ \\
\hline Throat pain & $20(39.2)$ \\
\hline Hoarseness & $18(35.3)$ \\
\hline Chronic cough & $17(33.3)$ \\
\hline Sputum & $5(9.8)$ \\
\hline Asthma & $1(2.0)$ \\
\hline Recurrent rhinitis & $2(3.9)$ \\
\hline Non-cardiac chest pain & $8(15.7)$ \\
\hline Headache & $2(3.9)$ \\
\hline Typical symptoms (heartburn or regurgitation) & $48(94.1)$ \\
\hline Extraesophageal symptoms & $47(92.2)$ \\
\hline Duration of acid-suppressive drugs (mo) & $61.5 \pm 83.2(2,480)$ \\
\hline$<6$ & $9(17.6)$ \\
\hline $12-60$ & $4(7.8)$ \\
\hline $12-60$ & $19(37.3)$ \\
\hline $60-120$ & $5(9.8)$ \\
\hline $120-240$ & $12(23.5)$ \\
\hline$\geq 240$ & $2(3.9)$ \\
\hline \multicolumn{2}{|l|}{ Effect of acid-suppressive drugs } \\
\hline Excellent & $5(9.8)$ \\
\hline Good & $12(23.5)$ \\
\hline Fair & $9(17.6)$ \\
\hline Poor & $20(39.2)$ \\
\hline No effect & $5(9.8)$ \\
\hline
\end{tabular}

Values were expressed as $\mathrm{n}(\%)$ or mean $\pm \mathrm{SD}$ (range). 
and $17.6 \%$ patients were elderly aged over 70 years. There were 31 $(60.8 \%)$ patients with normal body weight, 2 (3.9\%) were underweight, and 18 (35.3\%) were overweight; no patient had a BMI above 30 , and thus, there were no cases of obesity.

Ten patients (19.6\%) had a history of abdominal surgery. The types of surgery were cholecystectomy, appendectomy, cesarean section, or ovarian tumor resection. Combined medical diseases were observed in 20 patients (39.2\%) and cardiovascular diseases such as hypertension and angina were found in 14 patients (27.5\%).

The average duration of gastroesophageal reflux symptoms was 126 months, and 8 patients (15.7\%) had symptoms for more than 20 years. The typical symptoms of GERD were heartburn and acid regurgitation in $84.3 \%$ and $92.2 \%$ of patients, respectively, and 48 patients $(94.1 \%)$ had at least one typical symptom. Atypical symptoms were observed in 47 patients (92.2\%), of which 37 experienced globus sensation (sensation of lump or foreign body in the throat), the most common atypical extraesophageal symptom. The average duration of use of acid-suppressive drugs was 61.5 months. One-third of the patients showed good response to PPI medication (Table 2).

\section{Diagnostic Workup Before Surgery}

Upper gastrointestinal endoscopy, barium esophagogastrography, esophageal manometry, and esophageal $\mathrm{pH}$ monitoring test were recommended for patients who were scheduled for anti-reflux surgery (Table 3).

On upper gastrointestinal endoscopy, hiatal hernia was detected in 16 patients $(33.3 \%)$ and Barrett's esophagus was observed in 3 patients (6.3\%). Grades A to D reflux esophagitis as per the Los Angeles classification were observed in 27 patients (56.3\%). The remaining 21 patients $(43.8 \%$ ) had non-erosive reflux disease.

On barium esophagogastrography, 13 patients (54.2\%) had radiologic gastroesophageal reflux, and one had a hiatal hernia. There were no cases of esophageal stricture or stenosis.

Esophageal manometry was performed to determine if there were any esophageal motility disorders. There was no esophageal motility disorder detected based on the manometry test. The average lower esophageal sphincter pressure was measured as 20 $\mathrm{mmHg}$.

The esophageal $\mathrm{pH}$ monitoring test is the most objective test for acid reflux. Depending on the institution, various methods such as 24-hour $\mathrm{pH}$ monitoring through esophageal catheterization, 48hour $\mathrm{pH}$ monitoring using a wireless sensor, or impedance $\mathrm{pH}$ monitoring were performed. Pathologic acid reflux, which was DeMeester score $>14.7$, was found in $50.0 \%$ of the 38 tested pa- tients.

\section{Results of Anti-reflux Surgery}

All anti-reflux surgeries in this study were performed laparoscopically and there was no open laparotomy or transthoracic surgery. There was no case of conversion to open surgery. Not only $360^{\circ}$ Nissen fundoplication but also partial fundoplication of $270^{\circ}$ or $180^{\circ}$ was accepted as a type of fundoplication. However, all 51 patients who were actually registered underwent Nissen fundoplication. The average operation time was 88 minutes (range, 50-120 minutes).

Among the surgical complications of anti-reflux surgery known to occur, short-term complications that may occur during or immediately after surgery include hemorrhage, esophageal and gastric injury, pneumothorax, and wound complications. Late complications include severe dysphagia, diaphragmatic hernia, gastric slippage, and incisional hernia. None of these surgical complications were reported in the 51 patients enrolled in the study.

Table 3. Pre-operative Diagnostic Evaluation

\begin{tabular}{|c|c|}
\hline Variables & Values \\
\hline Endoscopy & $48(94.1)$ \\
\hline \multicolumn{2}{|l|}{ Hiatal hernia } \\
\hline Yes & $16(33.3)$ \\
\hline No & $32(66.7)$ \\
\hline \multicolumn{2}{|l|}{ Barrett esophagus } \\
\hline Yes & $3(6.3)$ \\
\hline No & $45(93.8)$ \\
\hline \multicolumn{2}{|l|}{ Esophagitis } \\
\hline No & $21(43.8)$ \\
\hline LA-A & $21(43.8)$ \\
\hline LA-B & $5(10.4)$ \\
\hline LA-C & $1(2.1)$ \\
\hline LA-D & $0(0.0)$ \\
\hline Barium esophagography & $24(47.1)$ \\
\hline Gastroesophageal reflux & $13(54.2)$ \\
\hline Esophageal dysmotility & $0(0.0)$ \\
\hline Hiatal hernia & $1(4.2)$ \\
\hline Esophageal stricture & $0(0.0)$ \\
\hline Esophageal manometry & $38(74.5)$ \\
\hline LES pressure (mmHg) & $20.7 \pm 10.9(3.0,46.0)$ \\
\hline pH monitoring study & $38(74.5)$ \\
\hline DeMeester score & $36.8 \pm 68.9(0.9,400.8)$ \\
\hline $\begin{array}{l}\text { Pathologic acid reflux } \\
(\text { DeMeester score }>14.7)\end{array}$ & $19(50.0)$ \\
\hline
\end{tabular}

LA, Los Angeles classification; LES, lower esophageal sphincter. Values were expressed as $\mathrm{n}(\%)$ or mean $\pm \mathrm{SD}$ (range). 
Table 4. Changes in Gastroesophageal Reflux Disease Symptoms After Anti-reflux Surgery

\begin{tabular}{|c|c|c|c|}
\hline \multicolumn{2}{|c|}{ GERD symptoms } & \multirow{2}{*}{$\frac{1 \mathrm{wk}}{36(83.7)}$} & \multirow{2}{*}{$\frac{3 \mathrm{mo}}{29(87.9)}$} \\
\hline Heartburn $(n=43)$ & Complete resolution & & \\
\hline & Partial resolution & $5(11.6)$ & $3(9.1)$ \\
\hline & No change & $2(4.7)$ & $1(3.0)$ \\
\hline & Worsened & $0(0.0)$ & $0(0.0)$ \\
\hline \multirow[t]{4}{*}{ Regurgitation $(n=46)$} & Complete resolution & $35(76.1)$ & $29(82.9)$ \\
\hline & Partial resolution & $11(23.9)$ & $4(11.4)$ \\
\hline & No change & $0(0.0)$ & $2(5.7)$ \\
\hline & Worsened & $0(0.0)$ & $0(0.0)$ \\
\hline \multirow[t]{4}{*}{ Dysphagia $(\mathrm{n}=8)$} & Complete resolution & $1(12.5)$ & $5(100)$ \\
\hline & Partial resolution & $6(75.0)$ & $0(0.0)$ \\
\hline & No change & $1(12.5)$ & $0(0.0)$ \\
\hline & Worsened & $0(0.0)$ & $0(0.0)$ \\
\hline \multirow[t]{4}{*}{ Atypical symptom $(\mathrm{n}=46)$} & Complete resolution & $18(39.1)$ & $15(45.5)$ \\
\hline & Partial resolution & $21(45.7)$ & $12(36.4)$ \\
\hline & No change & $4(8.7)$ & $4(12.1)$ \\
\hline & Worsened & $3(6.5)$ & $2(6.1)$ \\
\hline
\end{tabular}

GERD, gastroesophageal reflux disease.

Values were expressed as n (\%).

\section{Gastroesophageal Reflux Disease Symptoms After Anti-reflux Surgery}

Symptomatic improvement after anti-reflux surgery was assessed for 4 different symptoms: heartburn, acid regurgitation, dysphagia, and atypical symptoms (Table 4).

Heartburn completely improved in $83.7 \%$ and partially improved in $11.6 \%$ at 1 week after surgery, and completely improved in $87.9 \%$ and partially improved in $9.1 \%$ at 3 months after surgery.

Symptoms of acid regurgitation completely improved in $76.1 \%$ and partially improved in $23.9 \%$ immediately after surgery. In other words, all fundoplication patients experienced improvement in regurgitation symptoms after surgery. At 3 months, complete resolution of regurgitation was achieved in $82.9 \%$ and partial resolution in $11.4 \%$ patients. Most patients maintained the improvement in symptoms, but 2 patients $(5.7 \%)$ reported that they felt the same acid regurgitation symptoms as those before the operation.

Dysphagia as a GERD symptom was seen only in 8 patients, and symptoms were completely improved in all patients examined at 3 months follow-up.

Atypical symptoms were completely improved in $39.1 \%$ and partially improved in $45.7 \%$ patients immediately after surgery, and completely resolved in $45.5 \%$, and partially improved in $36.4 \%$ at 3 months after surgery. The incidence rate of complete resolution was lower for atypical symptoms than in for typical symptoms of heartburn and acid regurgitation. Symptoms worsened in $6.5 \%$ of pa-
Table 5. Medication Usage After Surgery

\begin{tabular}{lcc}
\hline Medications & $1 \mathrm{wk}(\mathrm{n}=51)$ & $3 \mathrm{mo}(\mathrm{n}=37)$ \\
\hline No medication & $40(78.4)$ & $26(70.3)$ \\
PPI & $1(2.0)$ & $5(13.5)$ \\
H2RA & $4(7.8)$ & $2(5.4)$ \\
Prokinetics & $7(13.7)$ & $8(21.6)$ \\
\hline
\end{tabular}

PPI, proton pump inhibitor; H2RA, histamine $\mathrm{H} 2$ receptor antagonist. Values were expressed as n (\%).

tients immediately after surgery and in $6.1 \%$ of patients at 3 months after surgery.

Medications used after surgery are listed in Table 5. Five patients were administered with acid-suppressive medications (PPI or Histamine $\mathrm{H} 2$ receptor antagonist) at 1 week after surgery, and 7 patients administered at 3 months after surgery.

\section{Post-operative Adverse Symptoms}

Immediately after surgery, 37 patients $(72.5 \%)$ experienced dysphagia, and 3 months later, only 7 (18.9\%) experienced dysphagia. There was no case of severe dysphagia.

Symptoms such as the inability of belching are caused by the tightening of the lower esophagus, which is a common phenomenon in case with post-operative dysphagia. This adverse symptom presented in $19.6 \%$ at 1 week and $16.2 \%$ of patients at 3 months after surgery.

Symptoms related to gas in the gastrointestinal tract, such as 
bloating and frequent flatulence, appeared in $43.1 \%$ immediately after surgery and slightly decreased in $24.3 \%$ and $37.8 \%$ at 3 months. The changes of the proportion of patients without gas bloating and flatulence were not statistically significant $(P=0.227$ and $P=$ 0.791; Table 6).

\section{Quality of Life}

\section{Gastroesophageal reflux disease-related quality of life}

The heartburn score, regurgitation score, atypical score, and total GERD score were compared before and immediately after surgery and between 1 week after surgery and 3 months after surgery (Table 7). All scores significantly decreased at 1 week postoperatively $(P<0.001)$, and there was no change between 1 week and 3 months.

The questionnaire had one simple question asking whether the patient was satisfied with the current treatment, indicating patient satisfaction with medical treatment before surgery and with antireflux surgery after surgery (Figure). Although only $11.8 \%$ were satisfied with the medical treatment before surgery and $51.0 \%$ were dissatisfied with treatment at that time, $72.5 \%$ and $73.0 \%$ were satisfied with treatment at 1 week and 3 months after surgery, re-

Table 6. Post-operative Adverse Symptoms

\begin{tabular}{|c|c|c|c|c|}
\hline Adverse symptoms & & $1 \mathrm{wk}$ & $3 \mathrm{mo}$ & $P$-value ${ }^{\mathrm{a}}$ \\
\hline \multirow[t]{4}{*}{ Dysphagia (all patients) } & No & $14(27.5)$ & $30(81.1)$ & $<0.001$ \\
\hline & Mild & $26(51.0)$ & $6(16.2)$ & \\
\hline & Moderate & $5(9.8)$ & $1(2.7)$ & \\
\hline & Severe & $6(11.8)$ & $0(0.0)$ & \\
\hline \multirow{4}{*}{$\begin{array}{l}\text { Dysphagia } \\
\text { (patients without pre-operative dysphagia) }\end{array}$} & No & $10(30.3)$ & $26(78.8)$ & $<0.001$ \\
\hline & Mild & $15(45.5)$ & $6(18.2)$ & \\
\hline & Moderate & $3(9.1)$ & $1(3.0)$ & \\
\hline & Severe & $5(15.2)$ & $0(0.0)$ & \\
\hline \multirow[t]{4}{*}{ Difficulty belching } & No & $41(80.4)$ & $31(83.8)$ & 0.453 \\
\hline & Mild & $8(15.7)$ & $4(10.8)$ & \\
\hline & Moderate & $0(0.0)$ & $0(0.0)$ & \\
\hline & Severe & $2(3.9)$ & $2(5.4)$ & \\
\hline \multirow[t]{4}{*}{ Gas bloating } & No & $29(56.9)$ & $28(75.7)$ & 0.227 \\
\hline & Mild & $16(31.4)$ & $3(8.1)$ & \\
\hline & Moderate & $3(5.9)$ & $3(8.1)$ & \\
\hline & Severe & $3(5.9)$ & $3(8.1)$ & \\
\hline \multirow[t]{4}{*}{ Flatulence } & No & $29(56.9)$ & $23(62.2)$ & 0.791 \\
\hline & Mild & $14(27.5)$ & $8(21.6)$ & \\
\hline & Moderate & $4(7.8)$ & $3(8.1)$ & \\
\hline & Severe & $4(7.8)$ & $3(8.1)$ & \\
\hline
\end{tabular}

${ }^{a} \mathrm{McNemar}$ test was used to determine whether the proportion of patients without the adverse symptom was significantly changed.

Values were expressed as n (\%).

Table 7. Quality of Life Results Before and After Anti-reflux Surgery

\begin{tabular}{|c|c|c|c|c|c|c|}
\hline Variables & $\begin{array}{c}\text { Pre-operative } \\
\quad(\mathrm{n}=51)\end{array}$ & $\begin{array}{c}1 \mathrm{wk} \\
(\mathrm{n}=51)\end{array}$ & $P$-value ${ }^{\mathrm{a}}$ & $\begin{array}{c}1 \mathrm{wk} \\
(\mathrm{n}=37)\end{array}$ & $\begin{array}{c}3 \text { mo } \\
(\mathrm{n}=37)\end{array}$ & $P$-value ${ }^{\mathrm{a}}$ \\
\hline GERD score & $48.5 \pm 2.6$ & $9.6 \pm 1.6$ & $<0.001$ & $10.5 \pm 2.0$ & $8.7 \pm 1.9$ & 0.158 \\
\hline Heartburn score & $13.8 \pm 1.2$ & $1.7 \pm 0.7$ & $<0.001$ & $1.6 \pm 0.7$ & $1.3 \pm 0.6$ & 0.478 \\
\hline Regurgitation score & $16.5 \pm 1.0$ & $1.7 \pm 0.6$ & $<0.001$ & $2.1 \pm 0.8$ & $1.7 \pm 0.7$ & 0.524 \\
\hline Atypical symptom score & $17.0 \pm 1.1$ & $4.5 \pm 0.9$ & $<0.001$ & $5.1 \pm 1.1$ & $5.3 \pm 1.2$ & 0.843 \\
\hline EQ-5D & $0.72 \pm 0.02$ & $0.83 \pm 0.02$ & $<0.001$ & $0.82 \pm 0.02$ & $0.89 \pm 0.02$ & 0.008 \\
\hline HINT-8 & $0.75 \pm 0.01$ & $0.84 \pm 0.01$ & $<0.001$ & $0.84 \pm 0.01$ & $0.87 \pm 0.01$ & 0.426 \\
\hline
\end{tabular}

${ }^{a}$ Paired $t$ test.

GERD, gastroesophageal reflux disease; EQ-5D, European quality of life-5 dimensions; HINT-8, health-related quality of life instrument with 8 items.

Data are shown as the mean \pm SD. 


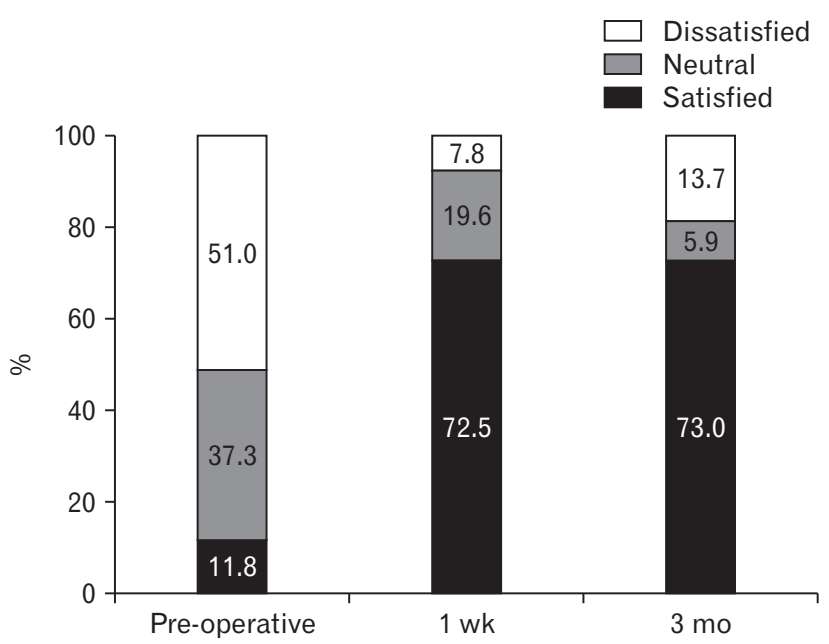

Figure. Satisfaction with current treatment for gastroesophageal reflux disease (for medical treatment before surgery ("pre-operative") and 1 week and 3 months after anti-reflux surgery ("1 wk" and " 3 mo," respectively).

spectively. Satisfaction with treatment was significantly higher after surgery than before surgery $(P<0.001, \mathrm{McNemar}$ test), and there was no significant difference between 1 week and 3 months after surgery $(P=1.000$, McNemar test $)$.

\section{General quality of life}

The EQ-5D QOL value was $0.72 \pm 0.02$ (mean $\pm \mathrm{SE}$ ) before surgery, $0.83 \pm 0.02$ at 1 week after surgery, and $0.89 \pm 0.02$ at 3 months after surgery. The QOL value measured by HINT-8 was $0.75 \pm 0.01$ before surgery, $0.84 \pm 0.01$ at 1 week after surgery, and $0.87 \pm 0.01$ at 3 months after surgery (Table 7).

Both measures of general QOL were increased at 1 week postoperatively compared with pre-operative measures $(P<0.001)$. EQ-5D value continued to increase at 3 months $(P=0.008)$ compared with 1 week after surgery, whereas HINT- 8 values remained unchanged.

\section{Discussion}

The prevalence of GERD has substantially increased in a few recent decades. ${ }^{8}$ This has been a common trend both in the Western countries and in Korea, making GERD one of the most common chronic benign diseases. According to a population-based study, it is estimated that $7.1 \%$ of Koreans experience GERD symptoms at least once a week. ${ }^{9}$ Although GERD prevalence in Korea is relatively lower than that in Western countries with the symptomatic prevalence of $20-25 \%,{ }^{10}$ the disease has been regarded as an impor- tant health problem even in Korea because of the enormous nationwide cost of medication and poor QOL of GERD patients.

Since the indication of anti-reflux surgery for GERD is established well in Western countries, laparoscopic anti-reflux surgery is the most common surgical procedure for upper gastrointestinal tract diseases. However, in Korea, almost all GERD patients undergo drug therapy owing to lack of awareness of anti-reflux surgery. Both patients and healthcare providers are considering GERD as a disease that can only be treated medically.

However, the interest of some gastrointestinal surgeons in anti-reflux surgery has increased and the number of operations for GERD has increased in Korea. Although the number of operations is much less than the number of operations in the Western countries, there have been several reports on the outcomes of anti-reflux surgery in Korea. ${ }^{2-5}$

The Korean anti-reflux surgery study group (KARS) conducted a nationwide survey among surgeons in Korea and reported the outcome of anti-reflux surgery in 87 patients. The results reported that laparoscopic fundoplication is an efficient treatment method for controlling GERD symptoms. ${ }^{3}$ Complete symptom control rates for typical and atypical symptoms were $86.3 \%$ and $63.3 \%$, respectively. ${ }^{3}$ Park et $\mathrm{al}^{2}$ reported the largest laparoscopic Nissen fundoplication data at a single institution in Korea; the complete control rate was $88.5 \%$ and the pre-operative response to PPI medication was the most important factor in determining the outcome of surgery.

All previous reports in Korea were of a retrospective case series nature. ${ }^{2-5}$ There has been no prospective study to date. The present study was the first multicenter prospective study evaluating the outcome of laparoscopic anti-reflux surgery in Korea.

Improvement or resolution of GERD symptoms by anti-reflux surgery in this study was almost the same as that reported in previous studies. ${ }^{2,311}$ Symptomatic improvement after anti-reflux surgery was different for different types of GERD symptoms. Almost all patients had typical symptoms and at the same time, most had atypical symptoms. In other words, most patients have both symptoms. Despite the high number of patients who did not respond to anti-reflux medication, the effect of anti-reflux surgery on typical GERD symptoms such as heartburn and acid regurgitation was very good. In contrast, atypical symptoms were not easily controlled by surgery. Atypical symptoms completely resolved in 45\% patients, whereas heartburn, a typical GERD symptom, resolved in $88 \%$. However, atypical symptoms were also improved by fundoplication, although the complete resolution rate of these was less likely than that of typical symptoms.

In the present study, no surgical complication was reported. 
There are several reasons for this low complication rate. Laparoscopic fundoplication is a minimally invasive surgery, and it is a clean surgery without gastrointestinal tract resection or bowel anastomosis. There is no surgical specimen to retrieve. Therefore, common complications of laparoscopic surgery such as intraoperative bleeding, infectious complication, and port site hernia are reported to be very rare. ${ }^{12}$

Specific complications associated with laparoscopic fundoplication are severe dysphagia caused by tight wrap, intrathoracic wrap migration, and wrap ischemia, which are common causes of revision surgery. The incidence of these wrap-related complications have been reported in $0.3 \%$ to $3.7 \%$ cases. ${ }^{12}$ However, no such finding has been reported in this study. There may be another reason for this. In particular, all surgeons participating in this study were surgeons who were mainly performing gastric or esophageal cancer surgery and were very familiar with the anatomy of the esophagogastric junction. In addition, surgery without complications may have been possible because of the sufficient experience of surgeons with fundoplication. This was different from previous studies in which surgeons' early experiences were included. ${ }^{2-5}$

The goal of anti-reflux surgery is to fix primary GERD symptoms and, at the same time, avoid additional adverse side effects. Therefore, for comprehensively assessing the outcome of anti-reflux surgery, in addition to the improvement of GERD symptoms, it is useful to evaluate patient satisfaction or general QOL that can assess post-fundoplication side effects. Especially, QOL is important for patients surviving for a long term after surgery. Early gastric cancer and benign diseases such as GERD are typical examples. Furthermore, it is difficult to obtain compliance with objective measures such as endoscopy, manometry, or $\mathrm{pH}$ monitoring because they are invasive tests. In contrast, QOL measures are more acceptable to patients, and high levels of compliance are possible.

Although laparoscopic fundoplication has been proven to be effective in controlling GERD symptoms, ${ }^{13}$ only a few studies demonstrate QOL after surgery. ${ }^{14-16}$ Regarding the evaluation of QOL after anti-reflux surgery, there is no consensus on the ideal QOL instrument. In general, it is a common practice to evaluate diseasespecific QOL and general QOL.

We used the EQ-5D and HINT-8, which are widely used general QOL measures, and GERD-HRQL, a GERD related QOL measure. GERD-HRQL questionnaire has been proven useful in measuring QOL after anti-reflux surgery for GERD. ${ }^{6,17} \mathrm{Un}$ fortunately, this questionnaire has not been validated in the Korean language; therefore, we used this questionnaire after modification, translation to Korean, and addition of symptom scores related to atypical GERD symptoms. Similar to previous reports, there was a significant improvement in post-operative GERD symptom scores.

GERD-HRQL correlated well with symptom score in a previous report. ${ }^{17,18}$ However, general QOL measure correlated poorly with clinical outcome measures, and its use to measure the outcome of anti-reflux surgery seemed to be questionable. ${ }^{17}$ The previous authors insisted that the disease-specific QOL measure was a better tool for evaluating surgical outcomes of anti-reflux surgery.

Nevertheless, EQ-5D and HINT-8, which are general QOL measures used in this study, reflect the improvement of post-operative symptoms and QOL. Scores for both general QOL measures improved significantly after anti-reflux surgery.

It can be presumed that surgery improved the general QOL score as a whole because the improved GERD symptoms were maintained unchanged at 1 week or 3 months after surgery, whereas the adverse symptoms such as post-operative transient dysphagia improved. Therefore, general QOL measures, especially the EQ5D score, which shows a continuous improvement from the first post-operative week to the third month, reflect the correlation between the effectiveness of the surgery and QOL.

There are several reasons for the improved overall QOL after surgery in this study, despite the short-term results. First, the preoperative baseline QOL may be lower than in other studies, since non-responders who did not respond to PPI were two-thirds of patients. Second, there were no complications of surgery and no severe adverse effects such as severe dysphagia, which are major factors leading to poor QOL after surgery. Third, there was no QOL reduction resulting from post-operative pain during the immediate post-operative period owing to the minimally invasive nature of the surgery.

In our study, the patients' treatment satisfaction significantly increased after surgery at any time point. Because the dysphagia and bloating symptoms, which were the side effects of surgery, were all temporary symptoms of the mild form and there was no severe symptomatic side effect caused by surgical error, the cause of dissatisfaction was mostly the atypical symptoms, which were not well controlled by anti-reflux surgery.

Therefore, the satisfaction with surgery and general QOL are proper outcome measures that show the overall effectiveness of surgery, including both resolution of GERD symptoms and improvement in adverse side effects.

There are several limitations of this study. First, although this study was a prospective study, it was difficult to obtain a comparative result of the treatment effect because the single cohort study was intended to compare the effect of anti-reflux surgery with that of 
pre-operative medical treatment. In fact, a comparison with medical treatment requires a randomized controlled trial that is designed for this. Second, the post-operative period for this study was not as long as 3 months. Long-term outcome studies should be performed separately. Third, follow-up examination of patients was based on symptomatic evaluation and QOL questionnaire. We did not evaluate patients post-operatively using endoscopy or $\mathrm{pH}$ monitoring within the study period. Thus, there was a lack of objective evidence of the improvement of reflux after fundoplication.

In conclusion, anti-reflux surgery significantly improved GERD symptoms and general QOL of patients without morbidity and mortality. A large proportion of patients were more satisfied with the therapeutic effect of anti-reflux surgery than with that of pre-operative medical treatment. Therefore, anti-reflux surgery is an effective treatment option compared with medical treatment with PPI for GERD patients selected for surgical treatment. However, further long-term follow-up studies including QOL data and objective diagnostic tests are still required.

\section{Supplementary Material}

Note: To access the supplementary table mentioned in this article, visit the online version of Journal of Neurogastroenterology and Motility at http://www.jnmjournal.org/, and at https://doi. org/10.5056/jnm19059.

Financial support: This research was supported by a grant of the Korea Health Technology R\&D Project through the Korea Health Industry Development Institute (KHIDI), funded by the Ministry of Health \& Welfare, Korea (Grant No. HC17C0050).

\section{Conflicts of interest: None.}

Author contributions: Joong-Min Park contributed to data analysis and interpretation, and wrote the manuscript; Sungsoo Park, Joong-Min Park, Kyung Won Seo, and Jin Won Kwon designed and coordinated the study; and Sungsoo Park, Joong-Min Park, Jin-Jo Kim, In-Seob Lee, and Sang-Uk Han recruited subjects and performed critical revision of the manuscript.

\section{References}

1. Galmiche JP, Hatlebakk J, Attwood S, et al. Laparoscopic antireflux surgery vs esomeprazole treatment for chronic GERD: the LOTUS randomized clinical trial. JAMA 2011;305:1969-1977.

2. Park JM, Kim BJ, Kim JG, Chi KC. Factors predicting outcomes of laparoscopic Nissen fundoplication for gastroesophageal reflux disease: experience at a single institution in Korea. Ann Surg Treat Res 2017;92:184190.

3. Lee JH, Park JM, Han SU, et al. Antireflux surgery in Korea: a nationwide study from 2011 to 2014. Gut Liver 2016;10:726-730.

4. Lee SK, Kim EK. Laparoscopic Nissen fundoplication in Korean patients with gastroesophageal reflux disease. Yonsei Med J 2009;50:89-94.

5. Lee SB, Jeon KM, Kim BS, Kim KC, Jung HY, Choi YB. Early experiences of minimally invasive surgery to treat gastroesophageal reflux disease. J Korean Surg Soc 2013;84:330-337.

6. Velanovich V. The development of the GERD-HRQL symptom severity instrument. Dis Esophagus 2007;20:130-134.

7. EuroQol Group. EuroQol--a new facility for the measurement of healthrelated quality of life. Health Policy 1990;16:199-208.

8. El-Serag HB, Sweet S, Winchester CC, Dent J. Update on the epidemiology of gastro-oesophageal reflux disease: a systematic review. Gut 2014;63:871-880.

9. Yang SY, Lee OY, Bak YT, et al. Prevalence of gastroesophageal reflux disease symptoms and uninvestigated dyspepsia in Korea: a populationbased study. Dig Dis Sci 2008;53:188-193.

10. Hummel K, Richards W. Endoscopic treatment of gastroesophageal reflux disease. Surg Clin North Am 2015;95:653-667.

11. Farrell TM, Richardson WS, Trus TL, Smith CD, Hunter JG. Response of atypical symptoms of gastro-oesophageal reflux to antireflux surgery. Br J Surg 2001;88:1649-1652.

12. Singhal T, Balakrishnan S, Hussain A, Grandy-Smith S, Paix A, ElHasani S. Management of complications after laparoscopic Nissen's fundoplication: a surgeon's perspective. Ann Surg Innov Res 2009;3:1.

13. Simorov A, Ranade A, Jones R, et al. Long-term patient outcomes after laparoscopic anti-reflux procedures. J Gastrointest Surg 2014;18:157162; discussion 162-163

14. Borie F, Zarzavadjian le Bian A, Millat B. Long-term quality of life in gastroesophageal reflux disease after NISSEN fundoplication: does it depend on preoperative responsiveness to proton pump inhibitors? Surg Laparosc Endosc Percutan Tech 2014;24:332-336.

15. Kellokumpu I, Voutilainen M, Haglund C, Färkkilä M, Roberts PJ, Kautiainen H. Quality of life following laparoscopic Nissen fundoplication: assessing short-term and long-term outcomes. World J Gastroenterol 2013;19:3810-3818.

16. Granderath FA, Kamolz T, Schweiger UM, Pointner R. Quality of life, surgical outcome, and patient satisfaction three years after laparoscopic Nissen fundoplication. World J Surg 2002;26:1234-1238.

17. Koetje JH, Nieuwenhuijs VB, Irvine T, Mayne GC, Watson DI. Measuring outcomes of laparoscopic anti-reflux surgery: quality of life versus symptom scores? World J Surg 2016;40:1137-1144.

18. Gee DW, Andreoli MT, Rattner DW. Measuring the effectiveness of laparoscopic antireflux surgery: long-term results. Arch Surg 2008;143:482-487. 